\title{
Mycological and Clinical Evaluation of Griseofulvin for Chronic Onychomycosis
}

\author{
R. R. DAVIES,* M.SC., PH.D. ; J. D. EVERALL, $\dagger$ M.R.C.P., M.R.C.S. ; ELIZABETH HAMILTON,*‡ B.sC., PH.D.
}

Brit. med. F., 1967, 3, 464-468

When griseofulvin became available in 1959 a critical evaluation of its use in chronic tinea of the nail was begun. Since then 122 patients have been treated with a standard dose $\$(0.5 \mathrm{~g}$. t.d.s. for one month followed by $0.5 \mathrm{~g}$. b.d.) for a minimum of six months and 74 for two years. As the trial progressed it became evident that a longer course of treatment was required than that suggested in earlier reports on the efficacy of the drug-namely, Williams et al. (1958) and Blank et al. (1959). It was therefore decided to treat for two years and to follow up the patient for a further year without treatment. Those failing to take the drug consistently throughout the lengthy period of treatment were transferred to an "intermittent-dose group."

\section{Methods}

At the patient's first visit numerous relevant clinical facts were recorded, and towards the end of the trial the blood and stool porphyrin levels were measured. All the nails of the hands and feet were examined mycologically and clinically, as were the soles, outer toe clefts, thumb crutches, and any other apparently affected site.

For the detailed mycological investigations parings were collected into sterile Petri dishes from all the nails, the clinically normal as well as the dystrophic, and skin scrapings were taken from the soles, webs, thumb crutches, and any other site that seemed to be infected. At least nine pieces of nail from each site were cultured-six in malt extract agar containing $40 \mu \mathrm{g}$. of chloramphenicol per $\mathrm{ml}$. and $0.5 \mathrm{mg}$. of cycloheximide per $\mathrm{ml}$. and three in peptone glucose agar containing $40 \mu \mathrm{g}$. of chloramphenicol per $\mathrm{ml}$. Three or four small pieces of nail from each site were examined by direct microscopy in $30 \%$ potassium hydroxide $(\mathrm{KOH})$. Skin scrapings were similarly investigated. The patients were thoroughly examined clinically at six-week intervals and the detailed mycological investigations were undertaken every six months.

When cultures were obtained the in-vitro sensitivities of the fungi were tested to investigate the possibility of their developing an increased resistance to the antibiotic during the course of treatment and to determine whether the sensitivity of the infecting organism to the antibiotic was reflected in the patient's response to therapy.

\section{Results}

When the trial was concluded 122 patients with mycologically proved onychomycosis had been treated for not less than six months. In $68(56 \%)$ the infecting organism was Trichophyton rubrum (Castellani) Sabouraud, and in 22 (18\%) it was T. mentagrophytes (Robin) Blanchard. From the nails of six patients both these species were isolated; and in 26, despite repeated attempts, no fungus was ever grown, though the

* Wright-Fleming Institute of Microbiology, St. Mary's Hospital Medical School, London W.2.

t Royal Marsden Hospital, London S.W.3.

Now at 65 Greencourt Road, Petts Wood, Kent

The griseofulvin used was that first available; this has since been replaced by a variant of the drug of finer particle size. presence of mycelium in $\mathrm{KOH}$ preparations was clear evidence of onychomycosis.

The number of patients treated with the standard dose or intermittent dose (defaulters) for various periods is shown in Table I.

\begin{tabular}{|c|c|c|c|c|c|c|c|}
\hline \multirow{2}{*}{ Fungus } & \multirow{2}{*}{ Dos $=$} & \multicolumn{4}{|c|}{ Months of Treatment } & \multicolumn{2}{|c|}{$\begin{array}{l}\text { Months } \\
\text { Followed }\end{array}$} \\
\hline & & 6 & 12 & 18 & 24 & 30 & 36 \\
\hline T. rubrum $\quad \cdots\{$ & $\begin{array}{l}\text { Standard } \\
\text { Intermittent }\end{array}$ & $\begin{array}{l}47 \\
21\end{array}$ & $\begin{array}{l}41 \\
20\end{array}$ & $\begin{array}{l}38 \\
16\end{array}$ & $\begin{array}{r}32 \\
9\end{array}$ & $\begin{array}{r}23 \\
8\end{array}$ & $\begin{array}{r}15 \\
6\end{array}$ \\
\hline T. mentagrophytes \{ & $\begin{array}{l}\text { Standard } \\
\text { Intermittent }\end{array}$ & $\begin{array}{r}7 \\
15\end{array}$ & $\begin{array}{r}7 \\
13\end{array}$ & $\begin{array}{r}5 \\
11\end{array}$ & $\begin{array}{r}4 \\
11\end{array}$ & $\begin{array}{l}3 \\
7\end{array}$ & $\begin{array}{l}0 \\
7\end{array}$ \\
\hline$T$. rubrum $+T . T$ & $\begin{array}{l}\text { Standard } \\
\text { Intermittent }\end{array}$ & $\begin{array}{l}4 \\
2\end{array}$ & $\begin{array}{l}4 \\
2\end{array}$ & $\begin{array}{l}4 \\
1\end{array}$ & $\begin{array}{l}4 \\
1\end{array}$ & $\begin{array}{l}1 \\
1\end{array}$ & $\begin{array}{l}1 \\
1\end{array}$ \\
\hline No culture group \{ & $\begin{array}{l}\text { Standard } \\
\text { Intermittent }\end{array}$ & $\begin{array}{r}5 \\
21\end{array}$ & $\begin{array}{r}4 \\
18\end{array}$ & $\begin{array}{r}3 \\
12\end{array}$ & $\begin{array}{r}2 \\
11\end{array}$ & $\begin{array}{l}2 \\
8\end{array}$ & $\begin{array}{l}2 \\
4\end{array}$ \\
\hline
\end{tabular}

Therapeutic Response in Patients with T.rubrum Infections

Response to treatment may be judged from two sets of criteria-by the clinical observation of dystrophy, and the mycological evidence of mycelium in $\mathrm{KOH}$ preparations or the isolation of dermatophyte fungi. When fungus is observed or is isolated from a dystrophic nail it is irrefutable evidence of infection; on the other hand the failure to discover fungus in the parings from a particular nail is not necessarily evidence that the whole nail is uninfected. However, where the nail has been repeatedly examined for fungus by two methods over a period of many months the possibility of missing an infection must be small, and in this respect it is noteworthy that during these studies dermatophyte fungi were found in clinically normal nails. Nail dystrophy, even in patients with some onychomycosis, is not necessarily due to fungal infection but might arise from a variety of causes. Since even a cosmetic improvement in the case of infected finger-nails is desirable, particularly in women, the clinical and more exact mycological findings are presented separately.

As T. rubrum was the commonest cause of onychomycosis in the patients studied, the response of those infected with this organism is described in detail; that of the other groups is briefly summarized.

\section{Nail Infections Before Treatment}

In 50 of the 68 patients onychomycosis involved both toenails and finger-nails, in 16 it was confined to the feet, and in 2 to the finger-nails alone. One patient, a 20 -year-old male Chinese student, seemed exceptional in that all the finger-nails of his right hand were severely dystrophic, and though $T$. rubrum was isolated from each of the nails it was never obtained from any other site despite repeated attempts, and there were no clinical signs of infection elsewhere. He was the only patient with a nail infection who did not also have an infection of the smooth skin when first seen. 
The percentages of patients, with the number of fingernails and toe-nails recorded from mycology or clinical observation as infected before treatment, are shown in Figs. 1 and 2. Of the patients presenting finger-nail infections $28(58 \%)$ were judged to have dystrophy of all their finger-nails, though, mycologically, the maximum number infected in any patient

\section{Therapeutic Response to Standard Dose}

Response to treatment (Figs. 3 and 4) is given as the percentage of patients showing an improvement, which for each subject has been calculated as a percentage of the maximum number of nails infected. After 24 months' treatment clinical

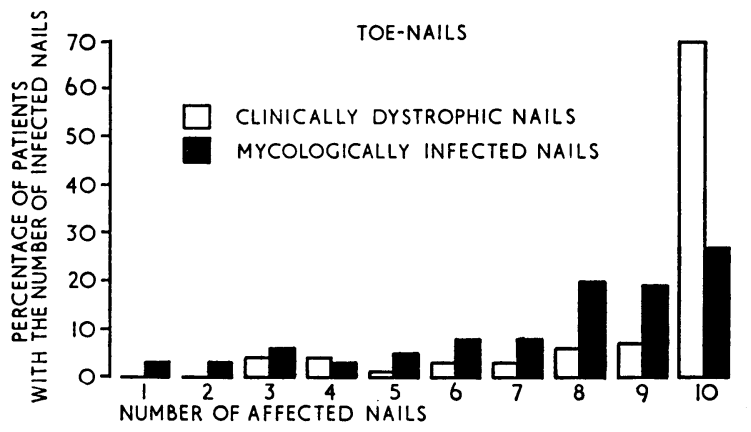

FIG. 2

Fig. 2.-Percentage of patients

TOE-NAILS

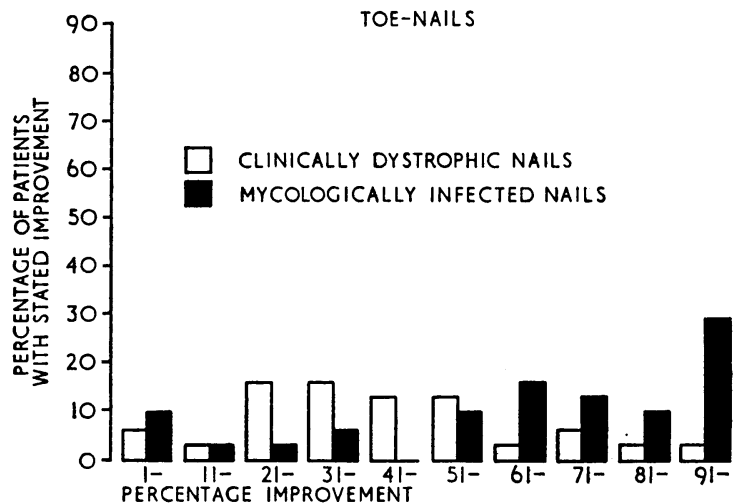

FIG. 4

Fig. 3.-Patients with T. rubrum infection of finger-nails treated with a standard dose of griseofulvin for two years; percentage showing improvement, which for each patient was calculated as a percentage of the maximum of nails infected. FIG. 4.- Patients with $T$. rubrum infection of toe-nails treated with a standard dose of griseofulvin for two years; percentage showing improvement, which for each patient was calculated as a percentage of the maximum of nails infected.

was eight, and only four (6\%) had as many as eight infected. The discrepancy between clinical observation and the mycological findings, though maintained throughout the trial, was less evident in toe-nail infections. Clinically, 48 (73\%) of the patients were judged to have all their toe-nails infected, whereas mycologically in only 17 (26\%) was this so.
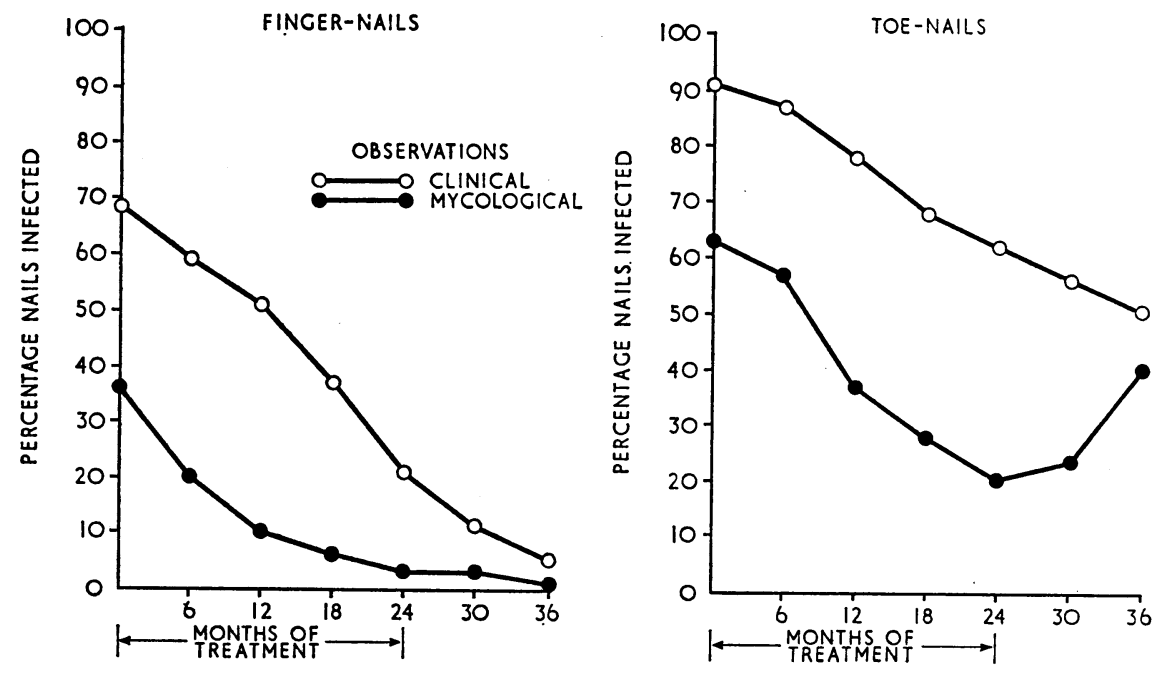

FIG. 5.-Percentage of infected nails in patients with $T$. rubrum infections treated with a standard dose of griseofulvin for 24 months and followed for another 12 months without treatment. cures were recorded in $12(40 \%)$ patients with finger-nail infections ; mycologically, $24(80 \%)$ were cured. With regard to toe-nail infections, while only 1 patient $(3 \%)$ was thought to be clinically cured, the mycological evidence showed that in $9(29 \%)$ patients cure was effected.

After 24 months, during which time each patient had taken $1 \mathrm{~g}$. of griseofulvin daily for 23 months, treatment was stopped and the patients were kept under observation for another year. It must here be emphasized that in the trial of a treatment " for a relatively rare" condition it takes many months to collect patients, and when after six years we decided to conclude the trial, though 74 patients had been treated for two years, only 53 had been followed for six months after treatment and 36 for the full year. Since the number treated and followed diminished steadily between 6 and 36 months, to determine the effect of treatment and its cessation in a group of patients the percentage of infected nails at each of the different time intervals is shown in Fig. 5.

On both clinical and mycological criteria the numbers of infected finger-nails decrease and show no evidence of relapse during and after treatment. With toe-nail infections the clinical observations reveal a steady 
improvement throughout, from $91 \%$ down to $62 \%$ of toe-nails infected at the end of treatment, down to $51 \%$ of the nails infected after a further year without treatment. The mycological evidence shows improvement from $63 \%$ of toe-nails infected before treatment down to $20 \%$ infected after two years' treatment. Six months after treatment was stopped a small rise to $23 \%$ of infected nails was recorded, but within a year infected, showing clear mycological evidence of relapse not apparent to the clinician.

\section{Thumb Crutch and Outer Toe Web Infections}

During the course of the trial it became apparent that in some patients outer toe web infections were persistent. The percentage of patients having both, one, or no thumb crutches infected and both, one, or no outer toe webs infected, as shown by mycological evidence after different periods of treatment and during the follow-up periods, is illustrated in Fig. 6.

After 12 months' treatment both thumb crutches were clear in over $75 \%$ of the patients, after two years $95 \%$ of the patients had clear thumb crutches, and there is no evidence of relapse of stopping treatment $40 \%$ of the nails were found to be

according to clinical and mycological criteria are given in Table II.

Clinically, no patient with a toe-nail infection was cured, but 5 out of 10 defaulting patients were cured of their fingernail infections. Mycologically, three out of eight patients examined after two years' treatment were cleared of toe-nail infections, but one relapsed and had four nails infected after six months without treatment. Another of these patients, who had 10 toe-nails mycologically infected at 12 months, had three infected at 24 months, one at 30 months, and 10 at 36 months. Both these cases presented mycological evidence of relapse in toe-nail infections when treatment was stopped. Mycologically, among five patients with finger-nail infections who were examined after 24 months two had infected nails, but one cleared during the follow-up period and the other was $86 \%$ improved.

\section{T. mentagrophytes Infections and Response to Treatment}

Of the 22 patients with nail infections due to this fungus only seven did not at some time default in taking the prescribed treatment, and none of these was followed for more than 30 months. As seven of the defaulters were followed for a year after treatment was stopped all the patients with infection due to this fungus are best considered together.

Of the 12 patients treated for two years with finger-nail infertions six showed a clinical cure and $10(83 \%)$ were mycologically clear. Thirteen patients with $T$. mentagrophytes infections of their toe-nails were treated for two years, and though no clinical cure was recorded six $(46 \%)$ were mycologically clear.

The percentage of nails found infected after different periods of treatment is given in Table III. The mycological results are biased in that among 13 patients three with toe-nail infections and one with a finger-nail infection grew worse during the period of treament. The mycological observations on patients with $T$. rubrum infections showed that no patient taking the standard dose of griseofulvin became worse, and among the $T$. rubrum-infected patients treated with an intermittent dose only one patient's toe-nails failed to show improvement.

during the year without treatment. With outer toe web infections, however, only $53 \%$ of the patients had clear toe webs after two years' treatment, $28 \%$ had both webs infected, and $19 \%$ had one web infected. A year after the cessation of treatment the proportion of patients with clear toe webs had fallen to $45 \%$, and the number of patients with both their outer toe webs infected had risen $45 \%$. There is therefore a relapse in the smooth-skin infections of the feet which parallels that observed with the toe-nails.

\section{Response to Intermittent Griseofulvin Treatment}

This smaller group of patients comprised those who were prescribed the standard dose but omitted to take the drug for periods varying from weeks to months during the lengthy period of treatment. The percentage of nails found infected

TABLE II.-T. rubrum Response to Intermittent Treatment

\begin{tabular}{|c|c|c|c|c|c|c|c|c|c|}
\hline \multirow{2}{*}{\multicolumn{2}{|c|}{ Observations }} & & \multicolumn{7}{|c|}{ Months Treated and Followed } \\
\hline & & & 0 & 6 & 12 & 18 & 24 & 30 & 36 \\
\hline \multicolumn{10}{|c|}{ Percentage of Toe-Nails Infected } \\
\hline $\begin{array}{l}\text { Clinical } \\
\text { Mycological .. }\end{array}$ & $\begin{array}{l}\ldots \\
\ldots\end{array}$ & $\therefore$ & $\begin{array}{l}76 \\
56\end{array}$ & $\begin{array}{l}52 \\
43\end{array}$ & $\begin{array}{l}69 \\
36\end{array}$ & $\begin{array}{l}64 \\
38\end{array}$ & $\begin{array}{l}68 \\
38\end{array}$ & $\begin{array}{l}56 \\
26\end{array}$ & $\begin{array}{l}64 \\
63\end{array}$ \\
\hline \multicolumn{10}{|c|}{ Fercentage of Finger-Nails Infected } \\
\hline $\begin{array}{ll}\text { Clinical } & . \\
\text { Mycological } & .\end{array}$ & . & .. & $\begin{array}{l}66 \\
43\end{array}$ & 44 & 25 & 16 & 33 & $\begin{array}{r}14 \\
0\end{array}$ & 13 \\
\hline
\end{tabular}

TABLE III.-T. mentagrophytes Response to Intermittent Treatment

\begin{tabular}{|c|c|c|c|c|c|c|c|c|c|}
\hline \multirow{2}{*}{\multicolumn{3}{|c|}{ Observations }} & \multicolumn{7}{|c|}{ Months Treated and Followed } \\
\hline & & & 0 & 6 & 12 & 18 & 24 & 30 & 36 \\
\hline \multicolumn{10}{|c|}{ Percentage of Toe-Nails Infected } \\
\hline $\begin{array}{l}\text { Clinical .. } \\
\text { Mycological }\end{array}$ & 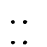 & 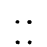 & $\begin{array}{l}88 \cdot \\
25\end{array}$ & $\begin{array}{l}75 \\
22\end{array}$ & $\begin{array}{l}70 \\
27\end{array}$ & $\begin{array}{l}66 \cdot 5 \\
14 \cdot 5\end{array}$ & $\begin{array}{l}36 \\
18\end{array}$ & $\begin{array}{l}56 \\
14\end{array}$ & $\begin{array}{l}49 \\
13\end{array}$ \\
\hline \multicolumn{10}{|c|}{ Percentage of Finger-Nails Infected } \\
\hline $\begin{array}{l}\text { Clinical .. } \\
\text { Mycological }\end{array}$ & 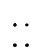 & $\because$ & $\begin{array}{l}54 \\
19\end{array}$ & $\begin{array}{r}28 \\
3\end{array}$ & $\begin{array}{l}32 \\
12\end{array}$ & $\begin{array}{r}24 \\
3\end{array}$ & 22 & $\begin{array}{l}24 \\
13\end{array}$ & $\begin{array}{l}23 \\
10\end{array}$ \\
\hline
\end{tabular}

\section{Mixed T. rubrum and T. mentagrophytes Infections}

Six patients had nails infected with both $T$. rubrum and $T$. mentagrophytes. From the nails of another three patients T. rubrum was isolated consistently at examinations during the course of treatment, and during the examination at the cessation of treatment $T$. mentagrophytes was found. There were also three patients in whom one of the species of Trichophyton was isolated from the nails and the other from the skin.

Before treatment the frequency with which $T$. rubrum was isolated relative to $T$. mentagrophytes from the nails of these patients was 22 to 9 ; after griseofulvin for a year or more 16 isolates of $T$. mentagrophytes were obtained to 14 of T. rubrum. It would therefore appear that $T$. mentagrophytes in nails is less susceptible to griseofulvin than is T. rubrum. 


\section{Onychomycosis-Fungus Unknown}

In 26 patients treated for over six months, while no fungus was isolated, a diagnosis of onychomycosis was confirmed when mycelium was observed in $\mathrm{KOH}$ preparations. Of these patients 13 were treated for two years-two with the standard dose and 11 with intermittent dosage-and six were followed for a year after treatment. Despite repeated attempts no fungus was isolated from the nails of these patients. The percentage of nails infected according to clinical and mycological criteria during the course of treatment and follow-up periods is given in Table IV.

TABLE IV.-Percentage of Toe-nails and Finger-nails Infected with Fungus not Isolated

\begin{tabular}{|c|c|c|c|c|c|c|c|c|c|}
\hline \multirow{2}{*}{\multicolumn{3}{|c|}{ Observations }} & \multicolumn{7}{|c|}{ Months Treated and Followed } \\
\hline & & & $\mathbf{0}$ & 6 & 12 & 18 & 24 & 30 & 36 \\
\hline \multicolumn{10}{|c|}{ Toe-nails } \\
\hline Clinical $\ldots$ & $\ldots$ & . & 92 & 58 & 70 & 61 & 59 & 54 & 60 \\
\hline Mycological & . & . & 30 & 11 & 7 & 15 & 6 & 8 & 0 \\
\hline \multicolumn{10}{|c|}{ Finger-nails } \\
\hline Clinical . & . & .. & 53 & 59 & 44 & 44 & $17 \cdot 5$ & 16 & 32 \\
\hline Mycological & . & . & 17 & 14 & 3 & 1 & 1 & 1 & 0 \\
\hline
\end{tabular}

The trial described was terminated in 1964. In October 1966 a questionary was sent to 74 patients who had been treated for two years. They were asked if their finger-nails and toe-nails were better or worse, how many were affected, whether they had any irritation or peeling or trouble with the skin of the hands or feet, and whether or not they had consulted a doctor and received treatment for any skin or nail infection.

Only 27 patients returned their forms correctly completed. Of these nine regarded their toe-nail infections as cured, but six of these were known to have had infected toe-nails when they were last seen. Among 18 patients reporting infected toenails five recorded a greater number of infected nails than when they were last seen. Another four stated that all their toe-nails were infected, as shown at their last visit to the clinic. From the patients' own descriptions of the state of their toenails nine seemed to be unchanged.

Only one patient reported a relapsed finger-nail infection, and he had shown a poor response to treatment throughout the course. Three patients reported peeling skin, four recorded irritation, and four had consulted a doctor.

\section{Toxicity}

No patient complained of serious subjective side-effects, but a few reported headaches, which ceased either spontaneously or when the tablets were taken with meals. No change in the red and white blood cell counts was observed in patients under treatment.

Griseofulvin when given to rats in large doses intravenously or intraperitoneally has been reported by Paget and Walpole (1958) to have colchicine-like effects on the seminal epithelium and bone marrow. With high dosage in mice, toxic liver damage occurs (De Matteis and Rimington, 1963), and prolonged intake of griseofulvin leads to the development of hepatoma in the enlarged liver (Hurst and Paget, 1963). Blood and stool porphyrin levels were determined in 84 of the patients in the present trial, and the results have been reported by Rimington et al. (1963). Faecal porphyrins were raised in 21 of 50 patients receiving treatment, and in 51 patients in whom erythrocyte porphyrins were determined normal maximum values were exceeded in 20. However, in four out of six patients with onychomycosis who had not been treated with griseofulvin total faecal porphyrins exceeded the normal, and in two blood coproporphyrin levels were slightly raised. Conventional liver-function tests on 10 patients with raised and
10 with normal porphyrin excretion showed no evidence ot abnormality.

\section{In vitro Sensitivity of $T$. rubrum and T. mentagrophytes to Griseofulvin}

Griseofulvin stock solutions in $50 \%$ acetone were sterilized by Seitz filtration, and serial dilutions were made in Sabouraud's glucose peptone agar. The concentrations employed to determine the minimum inhibitory concentrations for strains of $T$. rubrum ranged from 0.75 to $4 \mu \mathrm{g} . / \mathrm{ml}$. in $0.25-\mu \mathrm{g}$. steps. The inoculum was taken from a freshly grown colony, which when it had attained a diameter of $2 \mathrm{~cm}$. was scraped from the medium, added to $5 \mathrm{ml}$. of sterile distilled water in a tissue grinder, and after grinding transferred to a sterile container. Each of a series of plates containing griseofulvin, together with control plates, were then inoculated with three $0.02-\mathrm{ml}$. drops of the inoculum in random order. The cultures were incubated at $25^{\circ}$ C. and read after 10 days, and the next highest concentration to that on which growth was recorded was taken as the minimum inhibitory concentration. A total of 57 cultures obtained from patients before treatment and 186 from patients treated for a year or more were screened. The group of pretreatment isolates had a mean M.I.C. of 1.93 $\mu$ g. $/ \mathrm{ml}$. (S.D. 0.54), the group from treated patients a mean M.I.C. of $2.17 \mu \mathrm{g} . / \mathrm{ml}$. (S.D. 0.54). Student's $t$ test showed no significant difference between the means of the two groups at the 0.1 level. It may be concluded that in patients infected with $T$. rubrum failure to respond to treatment is not due to the fungus becoming resistant to the antibiotic.

The griseofulvin concentrations used to determine the minimum inhibitory concentrations for $T$. mentagrophytes ranged from 2.5 to $16.5 \mu \mathrm{g} . / \mathrm{ml}$. in $1-\mu \mathrm{g}$. steps, and cultures were read after seven days' incubation. The 19 isolates obtained from untreated patients had a mean M.I.C. of $4.8 \mu \mathrm{g} . / \mathrm{ml}$. (S.D. $4.68)$; 98 cultures from patients treated for a year or more had a mean M.I.C. of $7.17 \mu \mathrm{g} . / \mathrm{ml}$. (S.D. 9.37). Student's $t$ test showed no significant difference between the means of the two groups at the 0.2 level. In patients infected with T. mentagrophytes failure to respond to therapy is not due to the fungus becoming adapted to the antibiotic.

\section{Discussion and Conclusions}

In 1961 Ainsworth reported, " More than a hundred papers have been published to show that $1 \mathrm{~g}$. daily of griseofulvin taken orally effectively controls infection in man by diverse dermatophytes in all five continents." This has not been our experience in the study described. Most reports have been a clinician's account of his observations on a small number of patients over a brief period, and, apart from the investigation by Stevenson and Djavahiszwili (1961), even where a clinical diagnosis was confirmed mycologically no consistent mycological investigations appear to have been undertaken.

Alone in the present study have all the nails been repeatedly examined mycologically at regular intervals during and after treatment whether they were dystrophic or not. Stevenson and Djavahiszwili (1961), with $0.5 \mathrm{~g}$. of griseofulvin thrice daily, found that 5 out of 14 patients still had $T$. rubrum-infected toe-nails after 15 months' treatment. The two-year treatment in our trial is the longest one described. Both $1 \mathrm{~g}$. of griseofulvin daily for two years and $1.5 \mathrm{~g}$. daily for 15 months have been inadequate for the elimination of toe-nail infections due to T. rubrum. A small group of patients not shown in the results described gave a better response when treated with $1.5 \mathrm{~g}$ of griseofulvin daily, but some patients naturally respond better than others. In the follow-up the mycological evidence described showed relapse in toe-nails infected with $T$. rubrum before it was apparent to the clinician (Fig. 5). Among patients 
who completed questionaries two years later 18 recorded infected toe-nails and $5(28 \%)$ reported a greater number infected than when they were last seen.

Finger-nail infections showed a better response than toe-nails on both mycological and clinical criteria (Fig. 5), and there was no evidence of relapse during the follow-up. Among patients completing questionaries only one described a relapsed finger-nail infection, and he had shown little response to treatment. From the mycological evidence of thumb crutch and outer toe web infections due to $T$. rubrum, the response of smooth-skin infections parallels that of the nails. After two years $95 \%$ of the patients had clear thumb crutches, and there is no evidence of relapse during the year without treatment, whereas with outer toe web infections only $53 \%$ of the patients had clear toe webs after two years' treatment, and this fell to $45 \%$ during the year without treatment.

In no case could a patient's failure to respond to therapy be ascribed to the fungus becoming insensitive to the drug. The rate of growth of finger-nails was unrelated to therapeutic response, as also was the griseofulvin serum levels attained in a limited number of patients.

Mycological observation on patients with nails infected with $T$. mentagrophytes showed that some became worse during the course of treatment; this was not observed in patients with $T$. rubrum infections, and only one patient with a $T$. rubrum infection was not improved. In patients whose nails were infected with both these fungi the frequency with which $T$. mentagrophytes was isolated relative to T. rubrum increased during the course of treatment. It may be concluded, therefore, that in nails $T$. mentagrophytes is less likely to be inhibited by oral griseofulvin than $T$. rubrum; in-vitro tests showed that T. rubrum has a mean M.I.C. of $2 \mu \mathrm{g} . / \mathrm{ml}$., whereas that for $T$. mentagrophytes was $6.25 \mu \mathrm{g} . / \mathrm{ml}$.

The fact that toe-nail and outer toe web infections did not respond as well as finger-nail and thumb crutch infections may be due to a variety of causes. Gentles (1958) and Gentles et al. (1959) have shown that griseofulvin is incorporated in hair, where it presents a barrier to fungal penetration. There seems to be no record of griseofulvin having been recovered from human nails, or of the amounts in finger-nails versus toenails. The moisture content of the skin in the toe webs must, however, be higher than that of the thumb crutch, and the effect of sweat in leaching out griseofulvin from the tissues cannot be overlooked. The warm moist feet present a better ecological niche for fungal colonization than the hands, which tend to be drier and cooler, and this alone may account for early relapse in infections of the feet after the cessation of treatment when fungus has not been completely eradicated by the fungistatic antibiotic.

It has been found (Davies, in preparation) that finger-nail is more slowly hydrolysed by $\mathrm{KOH}$ than is toe-nail, and appears to be a more compact tissue into which griseofulvin may be incorporated as a barrier to fungal penetration. The fingers have a better blood supply than the feet, and finger-nails may consequently receive more griseofulvin, though while the fingernails grow more quickly than toe-nails it does not necessarily follow that the concentration of griseofulvin in the tissue is higher. What must be concluded, however, is that insufficient griseofulvin is incorporated in toe-nails with the dosages so far tried. Though the drug has a low toxicity with the dose regimen prescribed in the present study, it has affected blood and stool porphyrin levels. In high dosage it has colchicinelike effects on nuclear division, and any long-term toxic effect must await the test of time. Griseofulvin, however, must remain the treatment of choice for finger-nail infections, especially in women, but should never be prescribed for smooth skin infections, which are resolved with topical treatments, and its use in toe-nail infection is justifiable only when the patient has severe discomfort. Whether dosage with the new finerparticle-sized variant of the drug can be increased sufficiently to cure the chronic toe-nail infection without any deleterious effect remains to be seen.

\section{Summary}

Griseofulvin by mouth was used to treat 122 patients with chronic fungal infections of their nails for a minimum of six months; 74 received the drug continuously for two years, and 36 were followed for another year after the cessation of treatment to study relapse. Patients were assessed clinically at sixweek intervals and a detailed mycological investigation of all their nails, thumb crutches, and outer toe webs was undertaken before treatment and at six-monthly intervals thereafter. All patients were prescribed $0.5 \mathrm{~g}$. of griseofulvin t.d.s. for the first month, followed by 0.5 g. b.d. ; those failing to take the drug consistently were transferred to an intermittent-dose group. Treatment was found to be less effective in infections of the toenails and outer toe webs than in those of the finger-nails and thumb crutches, which showed a good response; a significant number of toe-nails and outer toe webs relapsed after treatment was stopped.

The response of patients with infections due to Trichophyton rubrum is described in detail, as they comprised the largest group ; that of patients infected with $T$. mentagrophytes, mixed infections due to both these fungi and of patients with chronic onychomycosis but from whom no fungus was isolated are only briefly described.

Response to therapy in nails infected with $T$. mentagrophytes is less favourable than in those infected with $T$. rubrum, and in nails infected with both these fungi $T$. mentagrophytes becomes dominant during treatment. In-vitro tests showed that $T$. mentagrophytes was less sensitive to griseofulvin than $T$. rubrum. Failure to respond to treatment could not be correlated with the sensitivity of the fungus isolated from any patient, and there was no evidence of the fungi developing an increased resistance to griseofulvin.

Observations on toxicity are discussed, and it is concluded that while griseofulvin is the treatment of choice for chronic finger-nail infections it should not be prescribed for smoothskin infections, which are resolved with topical treatments, and its use in toe-nail infections is justifiable only when the patient has severe discomfort.

We are indebted to Miss M. J. Denny and Miss C. Howard for technical assistance ; to the Imperial Chemical Industries Ltd. and the Govenors of St. Mary's Hospital for generous financial assistance; and to Mr. E. Hyde, of I.C.I., for his help with punched-card data recording and retrieval.

\section{REFERENCES}

Ainsworth, G. C. (1961). Nature (Lond.), 191, 12.

Blank, H., Smith, J. G., Roth, F. J., and Zaias, L. (1959). F. Amer. med.' Ass., 171, 2168 .

De Matteis, F., and Rimington, C. (1963). Brit. f. Derm., 75, 91. Gentles, J. C. (1958). Nature (Lond.), 182, 476.

Bentes, M. J., and Fantes, K. H. (1959). Ibid., 183, 256.

Hurst, E. W., and Paget, G. E. (1963). Brit. F. Derm., 75, 105.

Hurst, E. W., and Wagt, G. A. L. (1958). Nature (Lond.), 182, 1320.

Paget, G. E., and Walpole, A. L. (1958). Nature (Lond.), 182, 1320., R. R. (1963). Lancet, 2, 318.

R. R. (1963). and Djavahiszwili, N. (1961). Ibid., 1, 373.

Stevenson, C. J., and Diavahiszwili, N. (1961). Ibid., 1, 373.
Williams, D. I., Marten, R. H., and Sarkany, I. (1958). Ibid., 2, 1212. 